\title{
Long-term durability of CFRP under fatigue loading for marine applications
}

\author{
Antoine Le Guen-Geffroy ${ }^{1, *}$, Pierre-Yves Le Gac ${ }^{1}$, Malick Diakhate ${ }^{2}$, Bertrand Habert ${ }^{3}$, and Peter Davies ${ }^{1}$ \\ ${ }^{1}$ Ifremer, Laboratoire de Comportement de Structures en Mer, Pointe du diable, 29280 Plouzané, France \\ ${ }^{2}$ Univ. Bretagne Occidentale, IRDL-UMR CNRS 6027, F-29600 Morlaix, France \\ ${ }^{3}$ Direction Générale de l'Armement, Boulogne-Billancourt, France
}

\begin{abstract}
Composite propellers are a major new development in the marine transport industry. The use of composite materials in seawater turbines is also of great interest to the marine renewable energy industry. Those systems present similarities being both constantly immersed in seawater, under fatigue loadings, of large dimensions, and they are often designed using Carbon Fibre Reinforced Polymer (CFRP). Previous studies have shown sensitivity of some composite materials to the seawater environment mainly in the quasi-static loading domain. However, investigations now need to be performed on the behaviour of CFRP under seawater environment and fatigue loadings. In this study, CFRP samples were aged in natural seawater until saturation, in order to investigate the influence of water absorption on the fatigue properties of the material. Results showed a small decrease in fatigue lifetime under tension but a more significant drop for sample subjected to four point flexural fatigue.
\end{abstract}

\section{Introduction}

Global warming is a priority for a large part of the scientific community and many research programs. The impact on the environment and animals has been largely shown $[1,2]$. In order to limit global warming, simulations have shown the importance of limiting our production of greenhouse gases such as Nitrous Oxide $\left(\mathrm{N}_{2} \mathrm{O}\right)$, Methane $\left(\mathrm{CH}_{4}\right)$ or the most produced and studied: Carbon Dioxide $\left(\mathrm{CO}_{2}\right)$ $[3,4]$.

As a response, in the engineering domain, work is being performed to produce carbon-free energies [5]. Current and most popular in-use technologies are wind turbines, hydro-power dams and solar panels. Various studies are also examining marine renewable energies encouraged by huge energy production potential. Among others, we can cite offshore wind-turbines, Ocean Thermal Energy Conversion (OTEC), wave energy and tidal and stream energy [6-8]. Stream energy converters consist, for the most part, of turbines immersed in water converting current energy into electrical energy [9]. These systems are often comparable to wind turbines in principle but the dimensions are not comparable. Due to the higher density of water compared to air, Grogan et al. showed the importance of using carbon fibres composites (CFRP) instead of glass fibre composites (GFRP) [10].

There is also activity within the marine transport and freight industry, engineers tend to reduce the gas emissions. As in the automotive and aeronautical industries, the reduction of weight and the improvement of propulsion efficiency allow reductions in gases emissions. An active current subject is the use of composite materials to man-

*e-mail: antoine.le.guen.geffroy@ifremer.fr ufacture the propellers. Theoretical studies have shown multiple advantages as weight reduction -almost 50\%and propulsion efficiency[10-15].

Both of these subjects concern the use of fibrereinforced polymers to make rotating blades. Most of the design processes rely on either theoretical values or experimental values of unaged materials. However, these values tend not to be representative of material's properties throughout the system's lifetime. Indeed, composite materials have been shown to be sensitive to moisture and particularly to seawater [16-18]. For fatigue loadings, this could be characterized by a change in behaviour and the ultimate lifetime - if considered as existing [19, 20]could be overestimated. This could result in early failures of the systems.

In this paper, investigations are carried out both on the unreinforced matrix resin and its carbon fibre reinforced composite. Changes in behaviour are studied in the unaged, saturated and dried states of the materials. Epoxy resin appears to be highly sensible to seawater but it does not appear as clearly in tensile fatigue loadings of composites, as it will be shown below.

\section{Experimental}

\subsection{Materials}

The composite material studied here has been chosen to be representative of what could be used to manufacture tidal turbines and marine propeller blades. As noted above, the material of interest is a carbon fibre reinforced epoxy.

The RTM light process was chosen to be the more representative process for the large-scale fabrication of propeller and turbine blades. Then, the same process was used 
to fabricate experimental composite panels. Both composite panels and the mold were made by LoireTech. The two stacking sequences studied here were 10 plies unidirectional and $[(0 / 90 / 0 / 90 / 0) s]$. Fibre volume fraction was calculated using results from calcination made in a TGA apparatus and density measurements made in an helium pycnometer. Tests showed a fibre volume fraction of $50 \%$ $\pm 4 \%$ depending on the different panels used in the study.

The fibre reinforcements are Torayca T700 unidirectional supplied as $300 \mathrm{~g} / \mathrm{m}^{2}$ layers. They have a tensile modulus of $230 \mathrm{GPa}$ and an ultimate tensile strength of 4.9 GPa with $2.1 \%$ strain at break.

The matrix, from Sicomin, is a DGEBA-DGEBF epoxy-based resin SR8100 with a slow hardener SD4772. This resin is made for RTM light process meaning that its contact with air has to be limited to prevent unwanted reaction of the resin.

Resin was vertically cast between two aluminium plates covered by PTFE tape. A three-edge frame separating the two plates assured the thickness. This allowed the resin to harden while limiting the surface in contact with the air.

Both composite and resin panels were cured at room temperature for 24 hours. Then a first post cure cycle was applied at $60^{\circ} \mathrm{C}$ during 16 hours. The glass transition temperature $(\mathrm{Tg})$ resulting was found to be at $69 \pm 1{ }^{\circ} \mathrm{C}$. In order to obtain the maximum $\mathrm{Tg}$, a second post cure was applied at $120{ }^{\circ} \mathrm{C}$ for 2 hours resulting in a $\mathrm{Tg}$ of $78 \pm 1$ ${ }^{\circ} \mathrm{C}$. During this second post curing, to prevent reaction of the polymer with the external environment, panels were vacuum bagged.

Water uptake and Single End Notch Bend (SENB) resin samples, and the composite panels, were cut with a water-cooled diamond saw according to the required sample's dimensions. Dog-bone resin samples were cut by an automated 2-axis CNC machine according to 1BA dimensions from ISO 527-2. The CNC machine also allows surface machining of the plates to reduce the thickness of the samples making the plate from 3 to $1 \mathrm{~mm}$ in thickness.

\subsection{Fatigue apparatus}

To investigate on the influence of seawater ageing on the mechanical properties, it is necessary to develop specific methods and test equipment. The goal is to be representative of what the material undergoes when it is in use. Therefore, standardized tests have been adapted in seawater environment.

The two fatigue tests performed were tensile-tensile and four point flexure. For each type of fatigue loading, at least three specimens were tested initially to break at quasi-static rates. Then 3 to 4 different load levels were fatigue tested aiming to have at least three specimens per load level. A constant load ratio of $\mathrm{R}=0,1$ was taken.

\subsubsection{Tensile-Tensile tests}

Tensile-tensile tests were performed on an MTS $250 \mathrm{kN}$ hydraulic machine. Frequency was $1 \mathrm{~Hz}$ to limit selfheating of the sample as this can induce premature sample failures. As for the four-point flexure test apparatus, a specific apparatus was developed to allow tensile-tensile tests immersed in water. Previous studies tested successfully this apparatus for GFRP specimens. For CFRP, as strength and stress are much higher, the end conditions have to be modified. Tensile-tensile results presented here are for tests performed in air. A modified fixture is being developed and future works will investigate on the influence of immersion on tensile-tensile test performance. It should be noted that for GFRP the effect of wet ageing were considerably more significant than the influence of the test environment [21].

\subsubsection{Four-point flexural tests}

A specific test set-up developed at Ifremer allows immersion of four-point flexure samples in seawater. The standardized test from ASTM D6272 (one half support span and 32:1 span to depth ratio) was adapted and the apparatus was placed in an in-house developed seawater bath. This allows us to perform fatigue tests immersed in seawater. An aquarium heater regulates the temperature and an overflow system constantly recycles the water.

Control of the test is done by an hydraulic $25 \mathrm{kN}$ Zwick Roell test machine (Figure 1). Tests were done at a frequency of $2 \mathrm{~Hz}$.

Four point flexural loading was chosen because it involves a weak point of the composite; the compression response. The value of the maximum stress occurring in the middle -whether on top or on the bottom depending on the breakage- of the specimen is theoretically calculated by the equation from the standard as :

$$
\sigma=\frac{3}{4} \times L \times \frac{P}{b d^{2}}
$$

In this equation, $\sigma$ is the stress occurring on the specimen, $L$ is the span value, $P$ is the load and, $b$ and $d$ are respectively the width and the specimen's thickness. In our case, the support span $L$ was $100 \mathrm{~mm}$ and the specimens target dimensions were 120 by 25 by 3 millimetres.

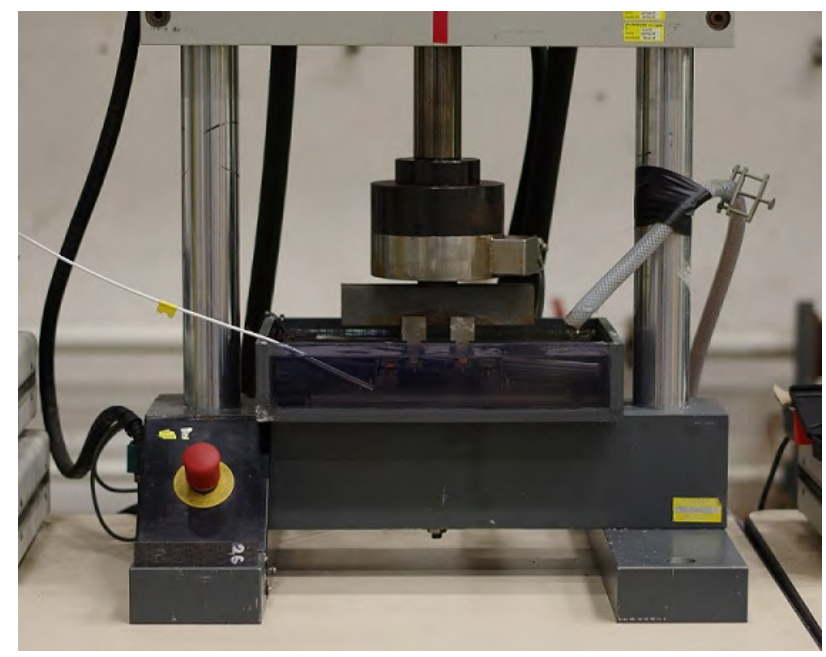

Figure 1: Immersed four point bending apparatus 


\subsection{Ageing conditions and experimental method}

To investigate the material's behaviour in marine environment, a common test is to follow its mass uptake while immersed in water. In this study, square coupons were immersed in constantly renewed natural seawater tanks developed at Ifremer. At regular intervals, samples are weighed after being dried on the surface with paper towel. Water uptake is expressed as the mass change in percent calculated as in equation 2. $\mathrm{M}(\mathrm{t})$ being the mass uptake value in $\%$ at time $t, m_{0}$ the initial mass and $m_{t}$ the mass at time $t$ (Figure 2 (a)).

$$
M(t)=\frac{m_{t}-m_{0}}{m_{0}} \times 100
$$
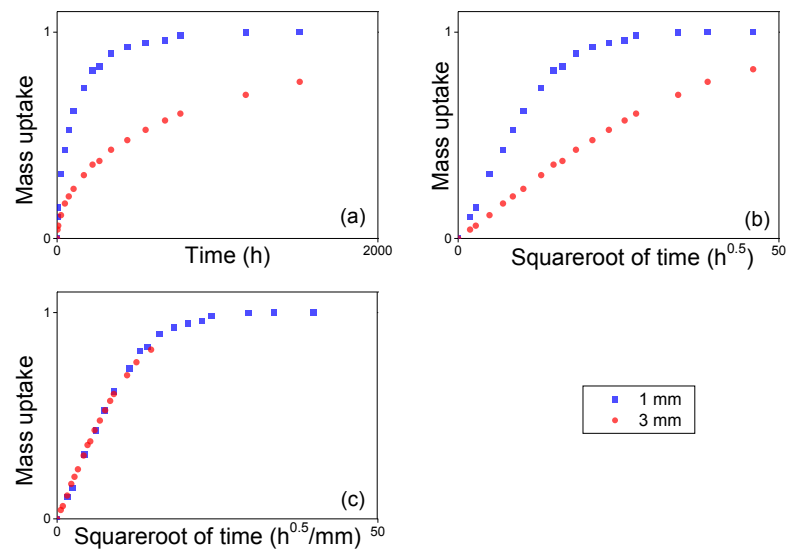

Figure 2: Illustration of Fick's law for normalized mass uptake of two resin samples of 1 and $3 \mathrm{~mm}$ thick in seawater at $40{ }^{\circ} \mathrm{C}$

Water uptake is then plotted vs square root of time. The goal is to identify diffusion laws in particular the applicability of Fick's diffusion law. There are two major characteristics of Fick's diffusion law to validate its identification. The first one is that, when it is plotted, the curve is linear at the start and reaches a plateau (Figure 2 (b)). The second point is that when plotting the mass uptake for two different thicknesses of test samples, if square root of immersion time is divided by the thickness, the two curves superpose (Figure 2 (c)).

\subsection{Acoustic Emission}

Acoustic emission is a powerful tool to monitor damage mechanisms such as fibre rupture or matrix cracking [2224] Other tools can monitor these phenomena, such as edge surface optical analysis or even tomography. Tomography is a powerful tool but it is expensive and difficult to use in situ. On the other hand, edge surface optical analysis presents good results and is less expensive than tomography but it only records the surface visible damages. Acoustic emission tend to be an intermediate tool for monitoring damage in the sample's entirety, is less expensive than the tomography and can be used in situ.
Under mechanical loading, cracking within the composite material generates transient elastic waves. A two channel AE system designed by MISTRAS group was used to record the waveforms generated during the laboratory fatigue tests. Two AE sensors (Micro 80 model) were used to also perform a linear localization of the acoustic sources (referred to as events).

Once the acoustic emission activity within the composite material is recorded, a post processing (cluster analysis) of the data is required to identify the acoustic signature of the different damage mechanisms. This classification aims mainly to identify the cracking mechanism (AE signature) that governs the damage evolution of the composite material.

A quasi-static load-unload tensile test was done starting from $30 \%$ of its load to break and increasing load by $5 \%$ (of the load to break) each time. This way we can identify acoustical signature of damage in the samples and re-use these criteria in fatigue tests to show damage evolution.

\section{Results}

\subsection{Water Uptake}

Composite coupons were aged for up to 6 months and neat resin ones for up to 3 months. Results showed a Fickian behaviour for both neat resin and composite.

An in-house developed routine, using Scilab's leastsq function, allowed the evaluation of diffusion coefficients $(D)$ and maximal water uptake $\left(M_{\infty}\right)$. An example of experimental and fitting curve can be seen in figure 3 .

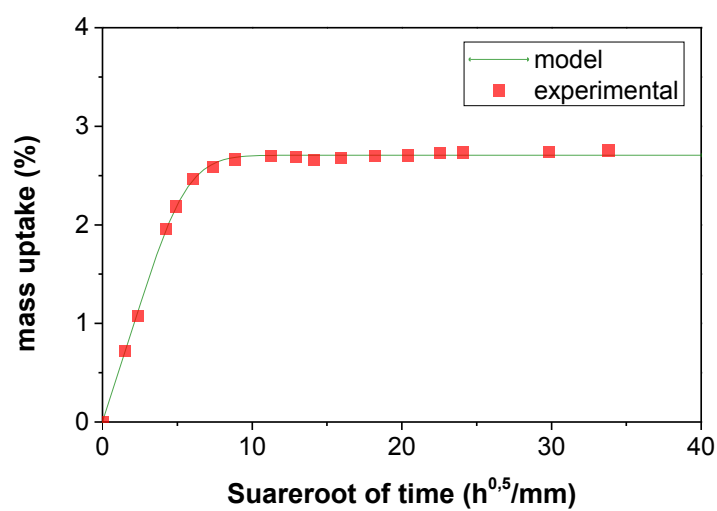

Figure 3: Fitted curve from Scilab routine on a neat resin sample at $60{ }^{\circ} \mathrm{C}$ in seawater

Results of corresponding $D$ and $M_{\infty}$ for the different conditions that are visible in Figure 4 are summed up in Table 1. Theoretical time-to-saturation $t_{\infty}$ (in days) for a sample of $1 \mathrm{~mm}$ in thickness is calculated from analytical equation 3 extracting $\mathrm{t}$, making $M_{t}=M_{\infty}$, and making the thickness $h=10^{-3} \mathrm{~m}$.

$$
t_{\infty}=\frac{M_{t}}{M_{\infty}} \times \frac{\pi}{16} \times \frac{h^{2}}{D}
$$




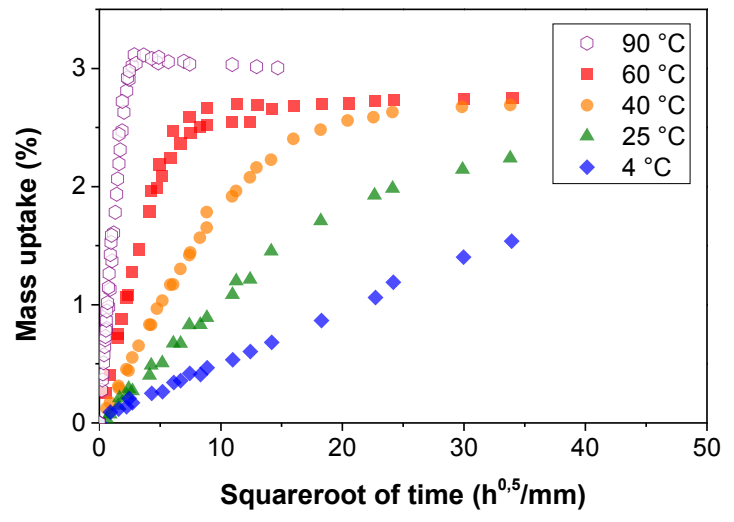

Figure 4: Neat resin seawater uptake for 1 and $3 \mathrm{~mm}$ thick samples at several temperatures

Table 1: Seawater uptake diffusion values on neat resin $(*$ estimated values)

\begin{tabular}{lcrrr}
\hline & $\begin{array}{c}\mathbf{D} \\
M_{\infty}(\boldsymbol{\%})\end{array}$ & $\begin{array}{r}T_{M_{\infty}} \\
(\mathbf{d a y s})\end{array}$ & $\begin{array}{r}\text { Least } \\
\text { Square }\end{array}$ \\
\hline $\mathbf{9 0}{ }^{\circ} \mathbf{C}$ & 110.50 & 3.06 & 0.8 & 0.27 \\
$\mathbf{6 0}^{\circ} \mathbf{C}$ & 16.59 & 2.70 & 7.2 & 0.05 \\
$\mathbf{4 0}^{\circ} \mathbf{C}$ & 2.81 & 2.61 & 42 & 0.29 \\
$\mathbf{2 5}^{\circ} \mathbf{C}$ & 1.25 & 2.17 & $96^{*}$ & 0.09 \\
$\mathbf{4}^{\circ} \mathbf{C}$ & 0.29 & $2.10^{*}$ & $419^{*}$ & 0.09 \\
\hline
\end{tabular}

For the composite ageing, water uptake in the carbon fibres is often considered to only depend on the resin fraction. The mass to saturation is then inferior and can be calculated from equation 4 with $M_{\infty c}$ being the mass to saturation of the composite, $V_{r}$ the mass content ratio of resin in the composite, in our case $V_{r}=0.41$, and $M_{\infty r}$ the mass to saturation of the neat resin.

$$
M_{\infty c}=V_{r} \times M_{\infty r}
$$

Theoretical values of diffusion coefficients of the composite $D_{c}$ can be calculated from various mixing factors found in the literature [25]. Here, we found that the Rayleigh factor presented better results for the samples that were saturated. The diffusion coefficient calculated with the Rayleigh factor is presented in equation 5 with $V_{f}$ being the volume fibre ratio and $D_{r}$ the resin diffusion coefficient.

$$
D_{c}=D_{r} \times \frac{1-V_{f}-0.3058 \times V_{f}^{4}}{\left(1+V_{f}-0.3058 \times V_{f}^{4}\right) \times\left(1-V_{f}\right)}
$$

Comparison of fitted $D$ and $M_{\infty}$ of the composite and theoretical $D_{t}$ and $M_{\infty t}$, calculated with equations 4 and 5, are shown in table 2 .

We can see that theoretical values of mass to saturation underestimate the water content for the composite but overestimate the diffusion coefficient. This could be explained by the void content in the composite that comes
Table 2: Seawater uptake diffusion values on composite(* estimated values)

\begin{tabular}{lcrrrr}
\hline & $\begin{array}{c}D \\
\left(10^{-13} \mathrm{~m}^{2} / \mathrm{s}\right)\end{array}$ & $D_{t}$ & $\begin{array}{r}M_{\infty} \\
(\%)\end{array}$ & $M_{\infty t}$ & $\begin{array}{r}\text { Least } \\
\text { Square }\end{array}$ \\
\hline $\mathbf{6 0}{ }^{\circ} \mathbf{C}$ & 9.71 & 11.22 & 1.36 & 1.10 & 0.14 \\
$\mathbf{4 0}^{\circ} \mathbf{C}$ & 1.86 & 1.89 & 1.34 & 1.07 & 0.16 \\
$\mathbf{2 5}^{\circ} \mathbf{C}$ & $0.29 *$ & 0.85 & $1.30 *$ & 0.89 & 0.02 \\
$\mathbf{4}^{\circ} \mathbf{C}$ & $0.07 *$ & 0.13 & $1.30^{*}$ & 0.86 & 0.04 \\
\hline
\end{tabular}

during the manufacturing process. Fibre/resin interface could also induce errors to the prediction values.

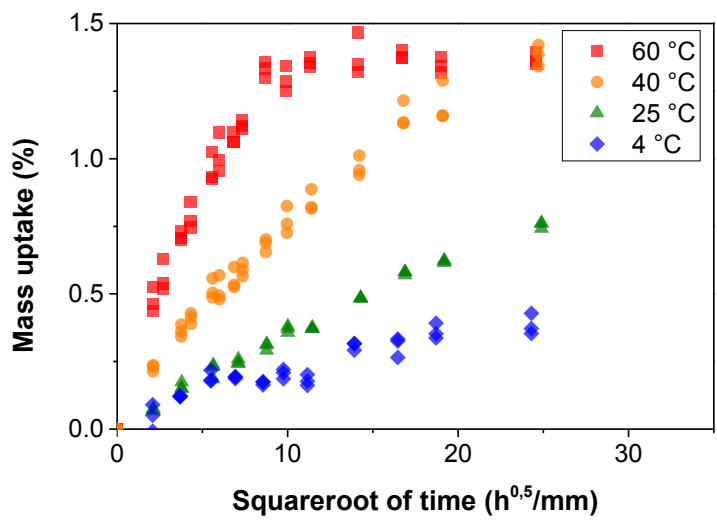

Figure 5: Water uptake in composite

\section{2 quasi-static}

\subsubsection{Neat-resin}

Neat resin specimens have been tested in three conditions: unaged, saturated and dried after being saturated. For the tensile tests, unaged and dried samples showed similarities in maximum strength and modulus. On the other hand, saturated samples showed a loss in maximum strength of almost $50 \%$ and strain at break went from $10 \%$ strain to over $25 \%$ strain (Figure 6).

These results suggest that there is plasticization induced by seawater absorption on the polymer based on mechanical response and reversibility.

Fracture tests results showed the same tendency. Initial properties were quite brittle and saturated specimens were more ductile. Drying the specimens after being saturated showed reversibility of the behaviour.

\subsubsection{Composite}

Composite were also tested in quasi-static loading in order to obtain ultimate values for fatigue tests. Specimens were tested in tensile for various orientations, in Inter-Laminar Shear Stress (ILSS) accordingly to ISO 14130 and in fourpoint flexure (FPF). Although there was an apparent sensibility of the resin due to water absorption, the effect of water on the composite was limited. (See Table 3) 


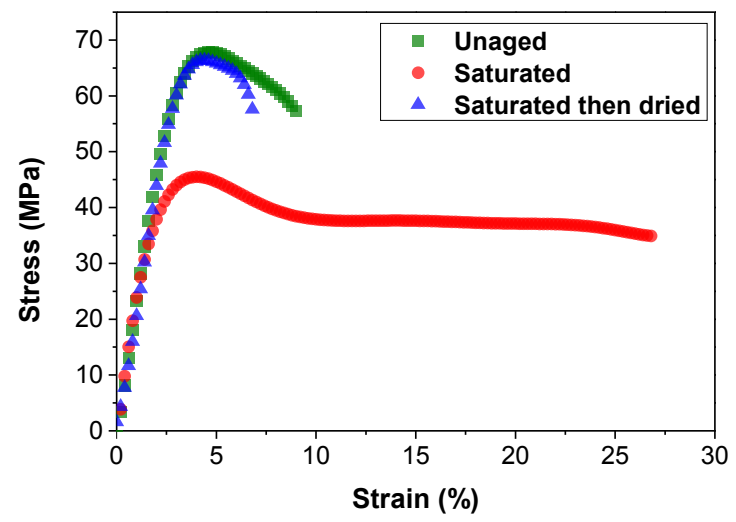

Figure 6: Tensile tests on unaged aged and dried neat resin

Table 3: Quasi-static properties of composite

\begin{tabular}{lrcc}
\hline Property & $\begin{array}{r}\text { Unaged value } \\
(\mathbf{M P a})\end{array}$ & $\begin{array}{r}\text { Aged } \\
\text { value } \\
(\mathbf{M P a})\end{array}$ & $\begin{array}{r}\text { Loss/gain } \\
(\%)\end{array}$ \\
\hline Tensile 0 $^{\circ}$ & $1190 \pm 78$ & & \\
Tensile 0/90 $^{\circ}$ & $989 \pm 45$ & $938 \pm 20$ & $-5,4$ \\
Tensile 90 $^{\circ}$ & $42 \pm 2$ & & \\
FPF 0/90 $^{\circ}$ & $740 \pm 46$ & $681 \pm 17$ & -8 \\
FPF 0 $^{\circ}$ & $849 \pm 29$ & & \\
ILSS $^{\circ}$ & $40 \pm 3$ & $35 \pm 3$ & $-14,3$ \\
\hline
\end{tabular}

\subsection{Fatigue}

\subsubsection{Tensile-Tensile}

Tensile-tensile fatigue tests were only done on $0 / 90^{\circ}$ stacking sequence. Samples were considered run out after 1 million cycles. When comparing fatigue properties in $\sigma_{\max }$ vs cycles to failure, saturated specimens showed almost equivalent performances. This phenomenon is to be considered knowing there is a 5\% loss in ultimate tensile strength. Sensitivity to water absorption is then obvious but not as much as might have been expected given the $40 \%$ loss in tensile for the neat resin.

When considering the failure mode, it appeared that for the unaged and aged specimens, delamination of the outer ply is predominant. Figure 8 shows the delamination of an unbroken sample. The damaging process seems to be the same at all levels, with small debonds progressing along the specimen's length up to full delamination of the outer ply. We can see that debonding occurs in strips. For manufacturing purposes, unidirectional fibres are meshed every $20 \mathrm{~mm}$ by a small polyester weft strand to maintain fibres orientation. This induces plies to debond by strips independently.

\subsubsection{Real time monitoring of damage evolution}

As stated previously cracking within composite material generates acoustic activity. This latter has been analyzed

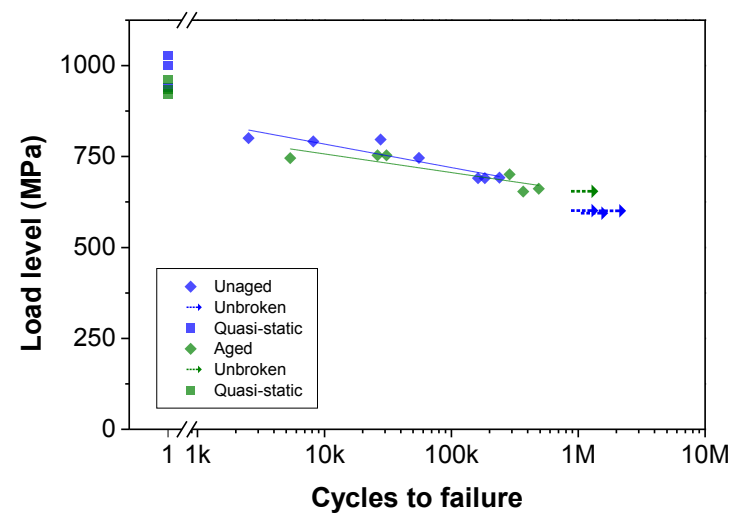

Figure 7: Tensile-Tensile results for unaged and aged 0/90 ${ }^{\circ}$ stack composite samples

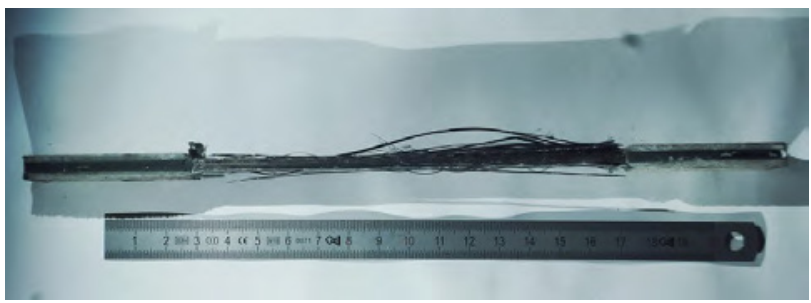

Figure 8: Example of fibre debonding on an unbroken fatigue sample

with the aim of better understanding the failure mechanisms involved in the composite material damage. In a first step of the AE data post processing, an unsupervised classification method is performed since it can allows gathering the AE events into clusters (Figure 9), and thus evaluating the number of failure mechanisms within the composite material

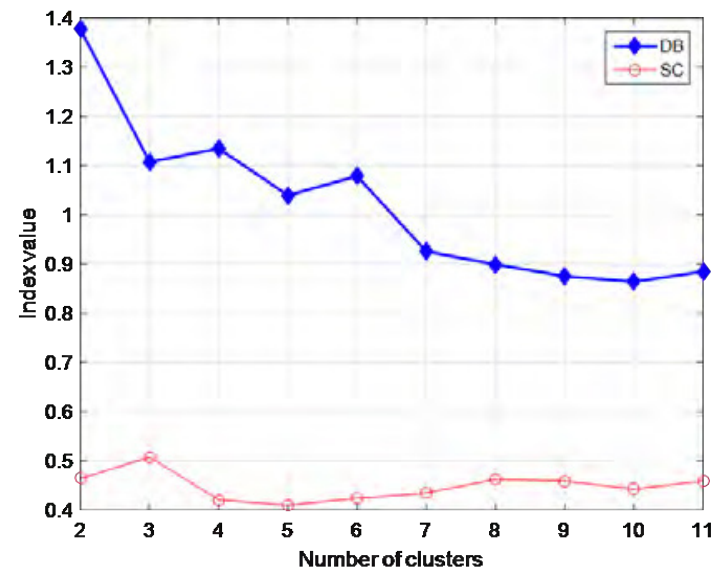

Figure 9: Evaluation of the optimal number of clusters

This unsupervised classification method, which used the k-means algorithm, has been successfully performed in previous studies to detect cracking mechanisms within 
composite material [22, 26], and to monitor crack tip growth within wood material $[27,28]$. A detailed description of this unsupervised method is available in these papers.

The AE data clustering aims, among other things, to propose the optimal number of clusters based on the values of two clustering evaluation indices: the DaviesBouldin (DB) and the Silhouette Coefficient(SC). The optimal number of clusters leads to a highest value of SC index and a lowest value of DB index (Figure 9). With these values, the clusters are dense and well separated, which corresponds to the standard concept of a cluster. From Figure 9 it can be concluded that the optimal number of clusters is three. In a previous study [22] results of cluster analysis on AE data from infused composite specimens exhibited three cracking mechanisms.

Cluster analysis on AE data from composite specimens shows a typical result (Figure 10), which show the projection of the three clusters of AE data onto a $2 \mathrm{D}$ plot. Clusters boundaries are identified.

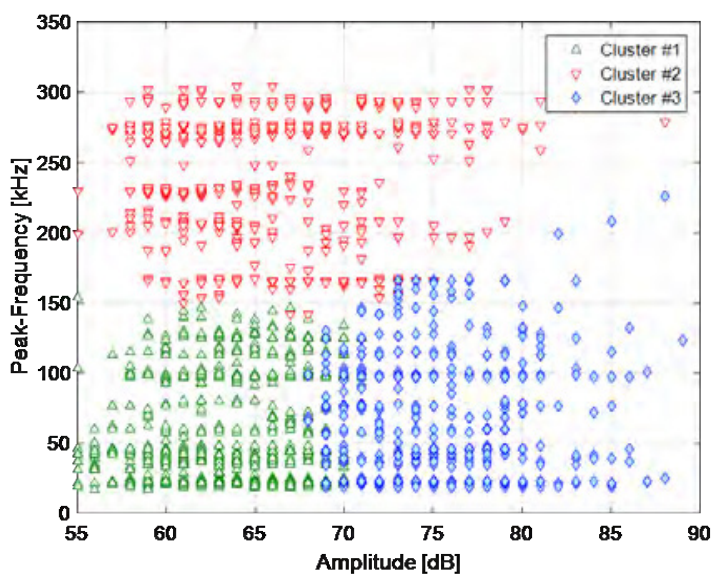

Figure 10: AE signatures of each damage mechanism cluster

Since this AE data clustering aims mainly to identify the cracking mechanism (AE signature) that governs the damage evolution of the composite material, AE events of Cluster 3 were selected, and the cumulative number of these events is compared with the evolution of the mechanical behaviour. This latter is analysed in terms of sample stiffness evolution during fatigue test (Figure 10).

On Figure 11 some changes in the slope of the cumulative number of events curve can be observed. These changes in slope can be detected in real time, and can be linked to damage evolution within the composite material. As a result, the change in slope can be selected as an experimental criterion to monitor damage evolution of the specimen.

\subsubsection{Four point flexure}

Four point flexural tests were performed on specimens in the unaged and aged states for up to 7 million cycles. As for tensile-tensile tests, there is a small loss in quasi-static

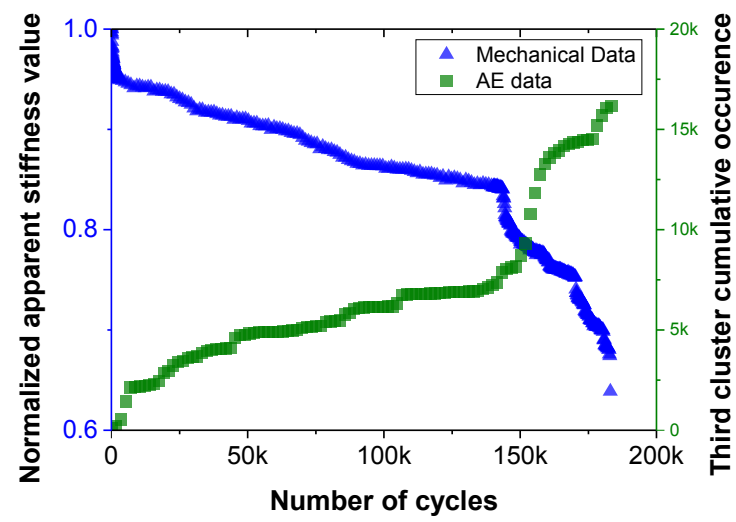

Figure 11: Evolution of AE events (cluster 3) during a fatigue test

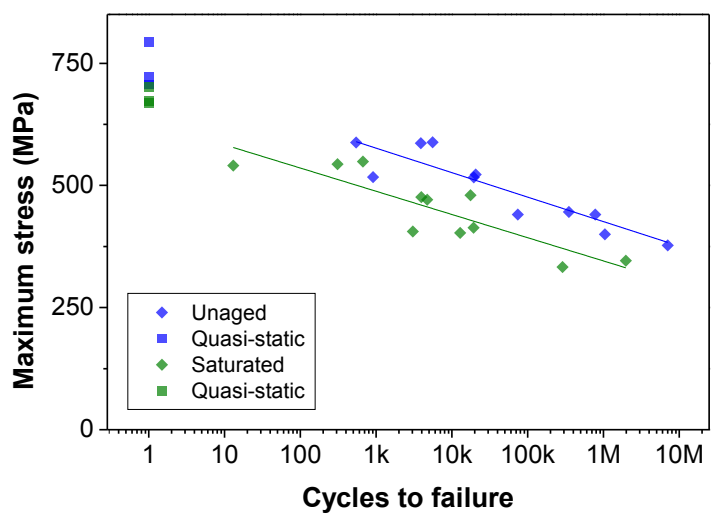

Figure 12: Four point flexure results for unaged and aged $0 / 90^{\circ}$ stack composite samples

strength values. For the fatigue tests, the composite appears to be more sensitive to seawater with a loss of approximatively one decade of lifetime compared to the unaged stress values (Figure 12). It should be noted that for a maximum stress of $50 \%$ in the unaged state, the cycles to failure of a sample were found to be 7 million cycles. If the shift is considered as true, in the saturated state, at a stress/strength value of $50 \%$, it should now fail at approximatively 700000 cycles. This is partly confirmed by one of the samples tested at $50 \%$ in the aged state that failed at 1.9 million cycles. This must be taken into account for the dimensioning of structures, but today only the unaged fatigue values are considered. A réécrie avec les valeurs actuelles

As mentioned above, the four point flexure test sollicitates the composite in tension and in compression. As composites are weaker in compression than in tension, sample usually break in compression. however, for the tests performed here, both unaged and after ageing, the composite did not break in compression or in tension. The dominating mechanism is delamination as shown in figure 13. 


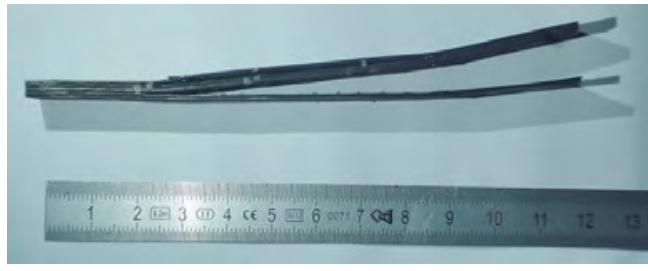

(a) Unaged

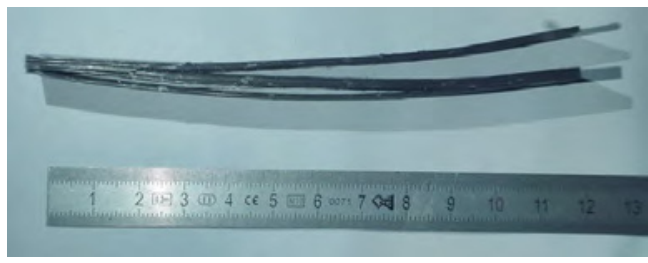

(b) aged

Figure 13: break faciès of two four point flexure samples

\section{Conclusion}

We showed in this study that CFRP composites are sensitive to a seawater environment, both under quasi-static and fatigue loading. The influence of the seawater environment on the fatigue properties is more marked for four point flexure fatigue results than for tension. A loss of one decade for the same stress values shows that dimensioning systems such as tidal turbine blades or marine propeller blades considering only the dried/unaged state values will not be conservative. It is therefore essential to take into account the impact of seawater environment and ageing on the properties of CFRP.

The out of plane properties, interlaminar shear strength and delamination in particular have shown to be the most sensitive to seawater. In tension, the outer surface showed debonded regions, while in four point flexure, the failure mode was clearly in interlaminar delamination. It seems important to conduct tests on the shear and delamination properties. Such properties can be quantified by standardized tests such as Double Cantilever Beam (CDB), Mixted Mode Bending (MMB) and, three and four Points Edge Notched bending tests (ENF \& 4ENF). These tests are now underway. An interesting subject would be to compare results from similar composites but containing z-pins or with three dimensions woven fibres

It should also be noted that in this study, the specimens where only immersed until fully saturated. Long term immersion of sample could reveal even higher impact of seawater on mechanical properties.

Acoustic emission showed promising results that needs more investigations. One acoustical signature was found suitable for damage monitoring. This signature can be followed in real time and interrupt tensile tests could allow us to link the acoustic signal to the mechanical damaging by performing tomographies. This way, the acoustic signature could be linked to a specific damage mechanism in the composite.

\section{Aknowledgment}

Authors would like to thanks the DGA and Ifremer for financial support and FabHéli project supported by Loiretech, Meca and Naval Group for material supply.

\section{References}

[1] L. Hughes, Trends in Ecology \& Evolution 15, 56 (2000)

[2] T.L. Root, J.T. Price, K.R. Hall, S.H. Schneider, C. Rosenzweig, J.A. Pounds, Nature 421, 57 (2003)

[3] P.M. Cox, R.A. Betts, C.D. Jones, S.A. Spall, I.J. Totterdell, Nature 408, 184 (2000)

[4] M. Meinshausen, N. Meinshausen, W. Hare, S.C.B. Raper, K. Frieler, R. Knutti, D.J. Frame, M.R. Allen, Nature 458, 1158 (2009)

[5] M.I. Hoffert, K. Caldeira, G. Benford, D.R. Criswell, C. Green, H. Herzog, A.K. Jain, H.S. Kheshgi, K.S. Lackner, J.S. Lewis et al., Science 298, 981 (2002)

[6] R. Pelc, R.M. Fujita, Marine Policy 26, 471 (2002)

[7] A.G. Borthwick, Engineering 2, 69 (2016)

[8] A.F.d.O. Falcão, Renewable and Sustainable Energy Reviews 14, 899 (2010)

[9] F.O. Rourke, F. Boyle, A. Reynolds, Renewable and Sustainable Energy Reviews 14, 1026 (2010)

[10] D. Grogan, S. Leen, C. Kennedy, C. Ó Brádaigh, Renewable Energy 57, 151 (2013)

[11] G. Marsh, Reinforced Plastics 48, 34 (2004)

[12] C.C. Lin, Y.J. Lee, C.S. Hung, Composite Structures 89, 206 (2009)

[13] M.R. Motley, Z. Liu, Y.L. Young, Composite Structures 90, 304 (2009)

[14] J.P. Blasques, C. Berggreen, P. Andersen, Marine Structures 23, 22 (2010)

[15] T. Taketani, K. Kimura, S. Ando, K. Yamamoto, Study on Performance of a Ship Propeller Using a Composite Material, in The Third International Symposium on Marine Propulsors smp (2013), Vol. 13, http://www .marinepropulsors.com/ proceedings/2013/11A.4.pdf

[16] P. Davies, Y.D. Rajapakse, eds., Durability of Composites in a Marine Environment 2, Vol. 245 of Solid Mechanics and Its Applications (Springer International Publishing, Cham, 2018), ISBN 9783-319-65144-6 978-3-319-65145-3, http : //link. springer . com/10.1007/978-3-319-65145-3

[17] P. Davies, G. Germain, B. Gaurier, A. Boisseau, D. Perreux, Philosophical Transactions of the Royal Society A: Mathematical, Physical and Engineering Sciences 371, 20120187 (2013)

[18] N. Tual, N. Carrere, P. Davies, T. Bonnemains, E. Lolive, Composites Part A: Applied Science and Manufacturing 78, 380 (2015)

[19] A. Hosoi, N. Sato, Y. Kusumoto, K. Fujiwara, H. Kawada, International Journal of Fatigue 32, 29 (2010)

[20] D. Backe, F. Balle, D. Eifler, Composites Science and Technology 106, 93 (2015) 
[21] A. Boisseau, P. Davies, F. Thiebaud, Applied Composite Materials 20, 145 (2013)

[22] M. Diakhate, N. Tual, N. Carrere, P. Davies, Cracking and Durability of Composites in a Marine Environment, in Challenges in Mechanics of Time Dependent Materials, Volume 2, edited by B. Antoun, A. Arzoumanidis, H.J. Qi, M. Silberstein, A. Amirkhizi, J. Furmanski, H. Lu (Springer International Publishing, Cham, 2017), pp. 1-8, ISBN 9783-319-41543-7

[23] L. Li, S.V. Lomov, X. Yan, V. Carvelli, Composite Structures 116, 286 (2014)

[24] S. Chaki, W. Harizi, G. Bourse, M. Ourak, Composites Part A: Applied Science and Manufacturing 78,
358 (2015)

[25] H.R. Dana, A. Perronnet, S. Fréour, P. Casari, F. Jacquemin, Journal of Composite Materials 47, 1081 (2013)

[26] L. Li, S.V. Lomov, X. Yan, Composite Structures 123, 45 (2015)

[27] M. Diakhate, E. Bastidas-Arteaga, R. Moutou Pitti, F. Schoefs, Engineering Fracture Mechanics 180, 254 (2017)

[28] M. Diakhate, N. Angellier, R. Moutou Pitti, F. Dubois, Construction and Building Materials 156, 911 (2017) 